\title{
Sulam Kerawang Gayo: Budaya Lokal, Bernilai Karakter dan Sebagai Identitas Bangsa
}

\author{
Sufandi Iswanto, Nurasiah, Hidayana Putri \\ sufandiiswanto@unsyiah.ac.id \\ Universitas Syiah Kuala, Banda Aceh \\ Pascasarjana UIN Syarif Hidayatullah
}

\begin{abstract}
Gayo filigree is one of the cultural outcomes of the Gayo community. In general, gayo people in particular and Aceh generally refer to Gayo filigree as a traditional fabric typical of the Gayo tribe. Gayo filigree itself is present in the midst of gayo society to meet physical and spiritual needs. Its motifs and colors have their own meaning and become the philosophy of people's lives. Gayo filigree comes with a long history. This research aims to describe gayo filigree local culture, the character values contained in each motif, and how gayo filigree can become a national identity. The method used is a qualitative method with an ethnographic study approach. The results of this study show that Gayo filigree is a native culture of the Gayo community, Gayo filigree has grown and developed since thousands of years ago in the scope of Gayo society. Initially, Gayo filigree was simply a reference to the motifs found in the cultural objects of the Gayo community, such as pottery, weaning, and wood carving in traditional houses. But since gayo people know textiles and embroidery art, Gayo filigree motifs are more identically referred to as traditional embroidery. From his motives, Gayo's filigree as a whole is very much a requirement of values and in line with the 18 character values contained in the 2013 curriculum. Gayo filigree is referred to as the identity of the nation, because it corresponds to the intent of national culture which is a culture that attaches importance to spiritual elements, feelings, and mutual help, because nilai-valuescontinue to develop. Tahun 2014 Gayo filigree has been designated as intangible culture or Indonesian Intangible Cultural Heritage.
\end{abstract}

Keywords : Filigree, Local Culture, Character Value, National Identity.

\begin{abstract}
Abstrak
Kerawang Gayo merupakan salah satu hasil kebudayaan dari masyarakat Gayo. Secara umum, masyarakat Gayo khususnya dan Aceh umumnya menyebut kerawang Gayo sebagai kain tradisional khas suku Gayo. Kerawang Gayo sendiri hadir di tengah-tengah masyarakat Gayo untuk memenuhi kebutuhan jasmani dan rohani. Motif dan warnanya memiliki makna tersendiri dan menjadi falsafah hidup masyarakat. Kerawang Gayo hadir dengan sejarah yang panjang. Penelitian ini bertujuan untuk mendeskripsikan budaya lokal kerawang Gayo, nilai-nilai karakter yang terkandung pada setiap motifnya, dan bagaimana bisa kerawang Gayo menjadi identitas bangsa. Metode yang digunakan adalah metode kualitatif dengan pendekatan studi etnografi. Hasil penelitian ini menunjukkan bahwa kerawang Gayo merupakan budaya asli masyarakat Gayo, kerawang Gayo telah tumbuh dan berkembang sejak ribuan tahun lalu dalam ruang lingkup masyarakat Gayo. Awalnya, kerawang Gayo hanyalah sebutan terhadap motif-motif yang terdapat pada benda-benda kebudayaan masyarakat Gayo, seperti pada gerabah, anyaman, dan ukiran kayu pada rumahrumah tradisional. Namun sejak masyarakat Gayo mengenal tekstil dan seni menyulam, motif kerawang Gayo lebih identik disebut sebagai kain sulam tradisional. Dari motifnya, kerawang Gayo secara
\end{abstract}


keseluruhan sangat syarat akan nilai-nilai dan sejalan dengan 18 nilai karakter yang terdapat pada kurikulum 2013. Kerawang Gayo disebut sebagai identitas bangsa, karena sesuai dengan maksud national culture yaitu budaya yang mementingkan unsur-unsur kerohanian, perasaan, dan saling membantu, karena nilai-nilainya terus berkembang. Tahun 2014 kerawang Gayo telah ditetapkan sebagai intangible culture atau Warisan Budaya Tak Benda Indonesia. Kata Kunci: Kerawang Gayo, Budaya Lokal, Nilai Karakter, Identitas Bangsa.

\section{Pendahuluan}

Manusia dan kebudayaan merupakan dua hal yang saling berhubungan dan tidak dapat dipisahkan. Tanpa budaya manusia tidak berarti apa-apa dan tanpa manusia budaya juga tidak akan ada. Begitu kuatnya hubungan manusia dengan kebudayaan. Keduanya telah terikat dalam dimensi ruang dan waktu yang menghasilkan sistem dalam kehidupan bermasyarakat. Kebudayaan merupakan sistem gagasan yang secara keseluruhan atau tindakan yang menghasilkan karya, semua itu dari manusia untuk bermasyarakat yang selanjutnya dijadikan sebagai milik munusia (masyarakat) itu sendiri dan semua kebudayaan itu didapatkan dengan cara belajar (Koentjaraningrat, 1990: Nurdien Harry Kistanto, 2015). Tujuan manusia untuk berkebudayaan tidak lain untuk dapat mewujudkan kehidupannya, dalam artian bahwa kebudayaan itu adalah alat manusia untuk memenuhi kebutuhannya baik jasmani maupun rohani ( Teuku Muda Aryadi, 2003; Panjaitan et al., 2014). Kedua kebutuhan tersebut merupakan kebutuhan pokok manusia dan saling berhubungan untuk dapat mencapai kesempurnaan kehidupan (Erlinda, 2016).

Kebudayaan disebut sebagai simbol yang menafsirkan perasaan dan nilai-nilai yang dibangun oleh manusia. Kebudayaan juga merupakan sebuah konsep bentuk simbol-simbol yang diwariskan, dan simbol tersebut merupakan ungkapan manusia untuk berkomukasi, melestarikan, dan mengembangkan pengetahuan mereka tentang kehidupan dan sikap manusia itu sendiri terhadap kehidupan (Geertz, 1992: Imam Baehaqie, 2014). Pendapat tersebut sesuai dengan tujuan pendidikan di Indonesia, yaitu pendidikan memiliki tujuan melestarikan, meningkatkan, menjaga, dengan pendidikan budaya bisa tetap berkembang. Budaya sangat penting dilestarikan sebagai pelambang manusia yang berakal dan berbudi. Maka tidak heran jika Ki Hajar Dewantara pernah mencetuskan sebuah konsep pendidikan budi pekerti dengan cara menginternalisasikan nilai-nilai dari budaya agar peserta didik terbiasa berbuat baik. Inilah mengapa budaya itu menjadi sesuatu yang perlu diajarkan pada peserta didik secara berkelanjutan.

Pendidikan berbasis budaya bukan merupakan hal yang baru, akan tetapi belakangan pendidikan budaya digandrung-gandrungkan kembali sebagai pendidikan syarat akan nilainilai, budaya dianggap bisa dijadikan sebagai filter pengaruh luar yang berdampak negatif bagi generasi muda. Dampak negatif tersebut bisa dilihat dari kemerosotan moral, yang belakangan menjadi isu utama yang dikaitkan dengan masalah pendidikan di Indonesia. Semua itu tidak terlepas dari pengaruh globalisasi dengan segala bentuk modernisme-nya yang telah membuat 
Sufandi Iswanto, Nurasiah, Hidayana Putri

Sulam Kerawang Gayo: Budaya Lokal, Bernilai Karakter dan Sebagai Identitas Bangsa

manusia tidak memiliki pegangan hidup. Padahal masyarakat Indonesia dikenal dengan budaya yang berbudi pekerti sebagaimana budaya ketimur-timuran.

Beranjak dari itu, salah satu hasil kebudayaan yang dapat dijadikan sebagai alat untuk pemenuh kebutuhan jasmani dan rohani suatu masyarakat adalah kerawang Gayo. Hasil budaya tersebut berupa kain tradisional yang terdapat pada masyarakat Gayo (suku bangsa Gayo) yang berdiam di dataran tinggi Gayo Provinsi Aceh. Kerawang Gayo adalah sebutan untuk jenis sulaman yang terdapat pada kain kerawang sendiri (Iswanto, Sufi, \& Abdullah, 2012; Rita Fitri, 2020). Hal ini bisa diartikan bawah kerawang Gayo merupakan motif yang terdapat pada kain tradisional suku bangsa Gayo. Bentuk motif pada kerawang Gayo dapat digolongkan sebagai jahitan mirip dengan renda, sebab motif tersebut langsung dikerjakan di atas kain yang masih polos, tanpa terlebih dahulu harus digambarkan dengan ragam hias (Asnah, 1996: Juliawati Ningsih, 2018). Pembuatan kerawang Gayo bisa dengan menggunakan jarum kail dan teknik yang digunakan dengan teknik tabour, yaitu jarum menembus bahan kain yang terentang kencang dalam bingkai kayu bulat dan mengangkat benang dibawahnya (Leigh, 1989). Dahulu pembuatan kerawang Gayo dikerjakan dengan cara tradisional dan peralatannya masih sangat sederhana. Namun pada saat ini, kebanyakan pembuatan kerawang Gayo telah menggunakan mesin jahit. Sehingga motif yang dibuat pada zaman dahulu dengan sekarang sedikit berbeda dan lebih sempurna.

Motif kerawang Gayo sendiri lebih banyak digunakan pada kain, oleh karena itu tidak heran jika kerawang Gayo sendiri identik dengan sebutan kain tradisional atau kain kebesaran masyarakat Gayo. Walaupun sebenarnya motif kerawang Gayo juga terdapat pada benda budaya lainnya. Motifnya juga terdapat pada rumah adat suku Gayo, kebanyakan motif ukir diambil dari alam sekeliling merekatinggal, serta adanya pengaruh dari pola kehidupan mereka sehari-hari (Shabri, 2000). Hampir semua motif yang diambil atau dipilih merupakan motif yang diambil berdasarkan pengamatan terhadap alam semesta. Motif kerawang Gayo memiliki makna filosofi yang mempunyai berbagai fungsi yang disesuaikan dengan kehidupan masyarakat setempat (Iswanto, 2012). Setiap motif memiliki pesan tersendiri yang berkaitan erat dengan aturan terhadap diri sendiri, hubungan antara manusia dengan sang pencipta, manusia dengan manusia, dan manusia dengan alamnya. Kerawang Gayo memiliki fungsi sebagai perlengkapan budaya yang digunakan pada acara-acara tertentu yang dianggap sakral. Selain pada kain dan rumah adat, motif kerawang Gayo juga terdapat pada benda-benda kebudayaan lainnya seperti pada gerabah dan anyaman.

Kerawang Gayo layak dikatakan sebagai budaya adiluhung, karena kerawang Gayo merupakan salah satu hasil budaya yang memiliki nilai tinggi dan nilai estetika juga tinggi. Pada motifnya terdapat nilai-nilai budaya yang layak dijadikan sebagai identitas bangsa Indonesia yang berbudi pekerti. Semua itu berkorelasi dengan nilai-nilai pendidikan karakter yang diterapkan di pendidikan Indonesia. Saat ini kerawang Gayo semakin banyak diminati karena motifnya memiliki gaya artistik yang indah. Para peminatnya bukan saja dari masyarakat Gayo sendiri, tetapi telah banyak diminati oleh masyarakat Indonesia dan masyarakat internasional. Masyarakat Gayo pada saat ini membuka home industri kerajinan kerawang gayo yang dijadikan sebagai penunjang ekonomi (mata pencaharian). Di Kabupaten Aceh Tengah ada dua kecamatan yang telah menjadi sentral pengrajin kerawang Gayo, yaitu Kecamatan Bebesen dan Kecamatan 
Kebayakan. Gayo dianggap sebagai kemahiran tradisional maka karena itu kerawang Gayo disebut sebagai bagian dari intangible cultural heritage. Berdasarkan uraian tersebut menjadi sangat penting kiranya untuk mengkaji kerawang Gayo, karena kerawang Gayo sendiri merupakan salah satu produk budaya masyarakat Gayo yang bagian dari masyarakat Indonesia. Pada setiap motif kerawang Gayo terdapat nilai-nilai karakter yang sesuai dengan 18 nilai-nilai karakter bangsa dan pada saat ini kerawang Gayo sudah menjadi bagian dari identitas bangsa Indonesia.

\section{Metode}

Metode yang digunakan dalam penelitian ini adalah metode kualitatif, dengan pendekatan studi etnografi. Metode penelitian kualitatif disebut juga sebagai metode penelitian yang naturalistik karena penelitiannya dilakukan pada kondisi yang alamiah (natural setting) (Sugiyono, 2010). Metode ini juga disebut sebagai metode etnografi, karena dalam perkembangan awalnya metode ini lebih banyak digunakan untuk penelitian bidang antropologi budaya. Selain itu disebut sebagai metode kualitatif karena teknik analisis datanya secara kualitatif.

Adapun rancangan tahapan-tahapan dalam rangkaian proses penelitian kualitatif menurut Bailey (1982) mulai dari memilih masalah, menyusun rancangan penelitian, melakukan pengumpulan data, membuat analisis data, dan melukukan interpretasi data (Bungin, 2003: J.R. Raco, 2010). Masalah yang muncul dalam penelitian ini adalah bagaimana munculnya sulam kerawang Gayo hingga memuat nilai-nilai karakter dan diakui sebagai identitas bangsa. Kerawang Gayo yang merupakan hasil budaya masa lalu terus berkembang, padahal banyak budaya Indonesia telah punah di era modernisme saat ini. Teknik pengumpulan data dalam penelitian ini adalah dengan metode library research (penelitian kepustakaan), yaitu dengan menggunakan referensi yang berasal dari buku, artikel, skripsi, tesis, dan internet yang berkaitan dengan topik pembahasan.

\section{Hasil dan Pembahasan}

Berdasarkan latar belakang historis, nenek moyang bangsa Indonesia yang sekarang menjadi kelompok-kelompok bangsa awal mulanya bermigrasi dari Utara yang telah terjadi pada masa prehistori. Mereka datang secara bergelombang dan menyebar keberbagai kawasan termasuk Indonesia. Migrasi yang berlangsung dari gelombang satu dengan gelombang berikutnya memiliki jarak interval waktu rata-rata 100 tahun. Setiap kelompok migran biasanya tidak langsung menuju tempat tujuan akhir, melainkan melakukan beberapa kali transit di tempat-tempat tertentu hingga sampai ketujuan akhir. Setiap kelompok migran tersebut selama perjalanan telah mengalami perubahan secara sendiri-sendiri. Kondisi ekologi telah membuat kelompok-kelompok mengalami perubahan sebagai bentuk adaptasi. Oleh karena itu, untuk setiap kelompok masyarakat memiliki perbedaan satu dengan yang lainnya (Mutakin, 1998: 2931). Pendapat tersebut juga kiranya menunjukkan bahwa kebudayaan lokal kiranya mengacu pada suatu kebudayaan yang tumbuh dan berkembang dalam suatu masyarakat yang selanjutnya mendapatkan pengakuan oleh masyarakat dalam ruang lingkup (lokal) tersebut. Hasil budaya tersebut semakin mendapatkan pengakuan oleh masyarakat luar karena budaya 
Sufandi Iswanto, Nurasiah, Hidayana Putri

Sulam Kerawang Gayo: Budaya Lokal, Bernilai Karakter dan Sebagai Identitas Bangsa

tersebut telah menjadi kebiasaan dan terus menerus diturunkan dari satu generasi ke generasi berikutnya. Seperti juga dengan beberapa kebudayaan masyarakat Gayo.

Suku Bangsa Gayo disebut juga sebagai urang Gayo yang merupakan salah satu suku bangsa yang ada di Indonesia. Suku Gayo mendiami Dataran Tinggi Gayo, sebuah kawasan yang berada di tengah-tengah Provinsi Aceh. Suku Gayo mempunyai kebudayaan, bahasa dan adatistiadat tersendiri yang berbeda dengan suku Bangsa Aceh pada umumnya (Rida Safuan Selian, 2007; Khalisuddin, Setyantoro, Gayosia, Bathin, \& As, 2012:). Kawasan Dataran Tinggi Gayo berada di tengah-tengah pegunungan Provinsi Aceh dan menyatu dengan bukit barisan, maka sangat cocok dijadikan sebagai lahan pertanian. Tidak heran jika sejak dahulu masyarakat Gayo umumnya hidup sebagai petani. Dahulu mereka mengelola pertanian secara tradisional dengan mengandalkan ilmu pengetahuan pengenalan ekosistem (Sufi \& Wibowo, 2013). Sejak zaman prasejarah, masyarakat Gayo telah mengembangkan kebudayaan sendiri yang disesuaikan dengan kondisi alam mereka tinggal. Pada saat agama Islam masuk, hampir semua unsur-unsur kebudayaan masyarakat Gayo telah disesuaikan dengan ajaran Islam, termasuk dengan sulam kerawang Gayo.

Sulam kerawang Gayo merupakan salah satu hasil budaya lokal dari sekian banyak budaya lokal suku bangsa lainnya di Indonesia. Kerawang Gayo adalah hasil kreasi suku Gayo, yang dulunya hanya bisa dipakai pada acara-acara tertentu saja, seperti acara perkawinan, khitan, turun kesawah, dan hari-hari besar keagamaan yang dianggap sakral (Iswanto, 2012). Biasanya dalam sebuah desa, hanya orang-orang tertentu saja yang memiliki kain sulam kerrawang Gayo. Para pengrajinnya juga tidak sebanyak sekarang, selain karena faktor sulitnya mendapatkan bahan juga tidak semua orang bisa membuatnya. Perlu adanya jiwa seni yang tinggi untuk dapat menyulam kerawang Gayo. Menurut Wiradnyana \& Setiawan(2011) dalam bukunya yang berjudul "Gayo Merangkai Identitas", motif kerawang Gayo telah ada dan berkembang dalam masyarakat Gayo sejak 7.400 tahun yang lalu. Walapun pada saat itu, motif-motif kerawang Gayo ditemukan pada benda-benda budaya Gayosepertigerabah. Dalam perkembangannya, setelah masyarakat Gayomengenal tekstil barulah motif kerawang Gayo mulai di aplikasikan pada benda-benda budaya kain, saatituhanya orang-orang tertentu saja yang bisa mengerjakan sulaman kerawang. Senada dengan itu menurut Fadhillah (1991: 1) kerawang Gayo akhirnya disebut sebagai salah satu wujud seni sulaman tradisional suku Gayo. Kerajinan tersebut dulunya hanya dikerjakan secara amatiran dan pada umumnya berkembang dikalangan keluargakeluarga tertentu saja. Keterampilan tersebut lambat laun terus berkembang karena diwariskan secara turun temurun dari generasi ke generasi. 


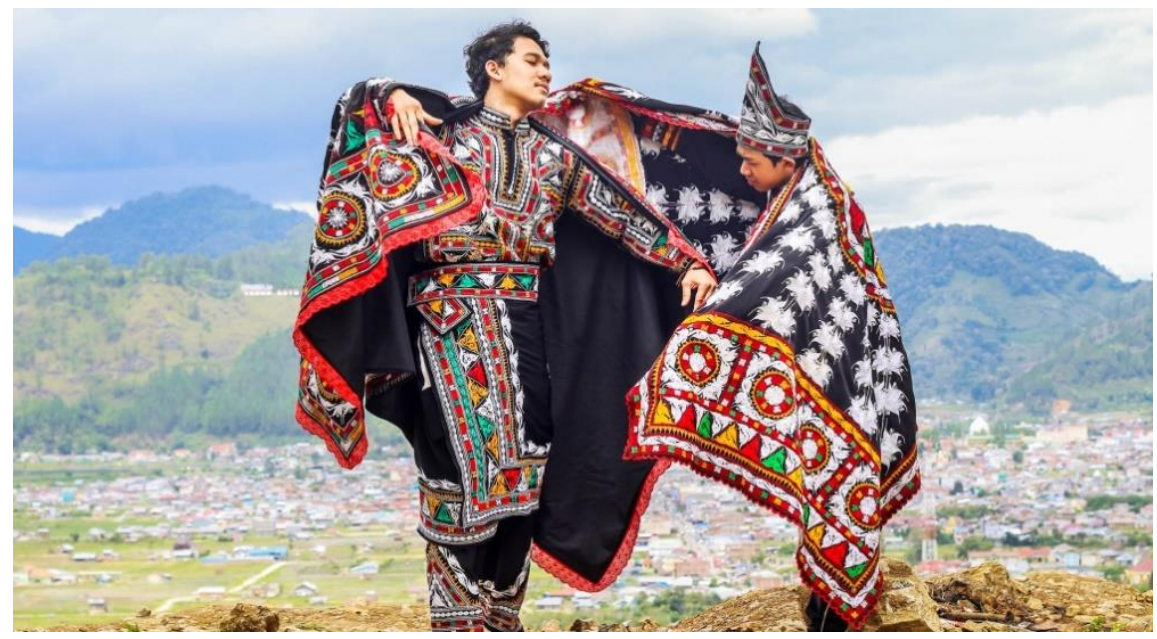

Gambar 1. Penari Guel menggunakan Kain Sulam Kerawang Gayo

Sumber: https:/ / travelinkmagz.com/wp-content/uploads/2018/09/Tanoh-Gayo_TariGuel_1920x1080px_1.jpg

Dengan demikian dapat disimpulkan bahwa kerawang Gayo merupakan asli hasil kebudayaan masyarakat Gayo yang telah tumbuh dan berkembang sejak zaman neolitik. Kerawang Gayo awalnya merupakan sebutan terhadap motif-motif kerawang, baik yang terdapat pada gerabah, kayu-kayu rumah adat, dan anyaman. Namun, karena motif tersebut dominan digunakan pada kain/tekstil (tenun) maka sejak itu masyarakat umumnya mengidentikkan jika kerrawang Gayo adalah kain tradisional atau kain kebesaran masyarakat Gayo. Warna dasar kain yang digunakan untuk menyulam motif kerawang Gayo harus kain berwarna hitam.

Pada dasarnya nilai mengacu pada sesuatu yang oleh manusia dan masyarakat dipandang sebagai yang paling berharga. Nilai itu berasal dari pandangan hidup suatu masyarakat. Pandangan hidup itu berasal dari sikap manusia terhadap Tuhan, terhadap alam semesta, dan terhadap sesamanya. Sikap tersebut dibentuk melalui berbagai pengalaman yang menandai sejarah kehidupan masyarakat yang bersangkutan ( M. Muslich, 2004; Maran, 2010). Dalam kehidupan manusia nilai juga dijadikan sebagai landasan, alasan, atau motivasi dalam bersikap dan bertingkahlaku, baik disadari atau tidak. Nilai sendiri bersifat abstrak yang hanya dapat dipahami, dipikirkan, dimengerti dan dihayati. Nilai juga berkaitan dengan harapan, cita-cita, keinginan dan segala suatu pertimbangan internal (batiniah) manusia (Prayitno \& Trubus, 2004).

Sedangkan karakter adalah suatu yang sangat penting dan vital bagi tercapainya tujuan hidup. Karakter merupakan dorongan pilihan untuk menentukan yang terbaik dalam hidup. Sebagai bangsa Indonesia setiap dorongan pilihan itu harus dilandasi oleh Pancasila (Samani \& Hariyanto, 2012). Karakter juga menjadi atribut atau ciri-ciri yang membentuk dan membedakan ciri pribadi, ciri etis, dan kompleksitas mental dari seseorang, suatu kelompok atau bangsa (Scerenco dalam Iswanto, Warto, \& Djono, 2015). Atributdan ciri-ciri tersebut dapat diidentifikasi pada prilaku individu yang bersifat unik, maka karakter sangat dekat dengan keperibadian seseorang. Dengan demikian dapat disimpulkan bahwa nilai dan karakter merupakan sesuatu 
Sufandi Iswanto, Nurasiah, Hidayana Putri

Sulam Kerawang Gayo: Budaya Lokal, Bernilai Karakter dan Sebagai Identitas Bangsa

yang penting dan vital dalam kehidupan bermasyarakat karena dianggap sebagai sesuatu yang berharga dalam menjalani kehidupan.

Nilai-nilai budaya yang merupakan sumber aturan dan merupakan pedoman hidup bagi suatu masyarakat dalam menjalankan aktivitasnya, sehingga kehidupan masyarakatnya bisa lebih teratur. Oleh karena itu, dalam suatu kebudayaan yang sama terdapat banyak pemikiran, sikap, dan tindakan sama yang diperlihatkan oleh masyarakat pendukung kebudayaan tersebut (Handoyo, 2015: M. Bahar Akkase Teng, 2017). Nilai-nilai karakter itu bisa diperoleh dari budaya dan budaya itu bisa didapatkan dari pendidikan, begitu juga sebaliknya. Pendidikan merupakan tempat terbaik dalam membangun dan mengembangkan pilar-pilar karakter dan budaya (Yaumi, 2014: I Ketut Sudarsana, 2017). Pendidikan budaya dan karakter bangsa dapat dimaknai sebagai pendidikan yang mengembangkan nilai-nilai budaya dan karakter bangsa sehingga peserta didik memiliki nilai dan karakter bangsa.

Kerawang Gayo salah satu hasil budaya lokal dan telah menjadi atribut suku Gayo, merupakan bentuk refresentasi nilai-nilai budaya sekaligus nilai-nilai karakter bangsa. Pada motif kerawang Gayo sendiri terdapat nilai-nilai yang sejalan dengan perumusan 18 nilai-nilai karakter dan pendidikan bangsa. Kurikulum 2013 terdapat 18 nilai karakter dan pendidikan bangsa antara lain: (1) religius; (2) jujur; (3) toleransi; (4) disiplin; (5) kerja keras; (6) kreatif; (7) mandiri; (8) demokrasi; (9) rasa ingin tahu; (10) semangat kebangsaan; (11) cinta tanah air; (12) menghargai prestasi; (13) persahabatan atau komunikatif; (14) cinta damai; (15) gemar membaca; (16) peduli lingkungan; (17) peduli sosial; dan (18) bertanggung jawab (Mustari, 2014; Yaumi, 2014). Mengacu pada 18 nilai tersebut, kerawang Gayo sendiri dibentuk atas kesadaran masyarakat Gayo terdahulu untuk dijadikan sebuah aturan dan landasan hidup baik untuk individu maupun dalam bermasyarakat. Sehingga secara keseluruhan dari motif kerawang Gayo syarat akan nilai-nilai karakter lokal yang sejalan dengan nilai-nilai karakter secara nasional. Adapun nilai-nilai karakter bangsa yang terdapat pada motif kerawang Gayo (Ferawati, 2013; Iswanto et al., 2015) adalah sebagai berikut:

\begin{tabular}{|c|c|c|}
\hline $\begin{array}{c}\text { Nama dan Bentuk } \\
\text { Motif }\end{array}$ & Nama Motif dan Filosofinya & Nilai-NilaiKarakter \\
\hline E⿻ & $\begin{array}{l}\text { Motif Matalo (matahari) melambangkan } \\
\text { hubungan antara manusia dengan Allah, } \\
\text { hubungan manusia dengan manusia dan } \\
\text { hubungan manusia dengan alam untuk } \\
\text { keselamatan. }\end{array}$ & $\begin{array}{l}\text { Motif tersebut syarat akan } \\
\text { nilai karaktersikap religius. }\end{array}$ \\
\hline प & $\begin{array}{l}\text { Motif Sarak Opat yang melambangkan Raja } \\
\text { (bersifat adil, bijaksana, penuh perhitungan } \\
\text { atas keputusan yang diambil), Petue (bersifat } \\
\text { menyelidiki dan mensiasati tentang } \\
\text { kehidupan masyarakat), Imem (melaksanakan } \\
\text { yang berhubungan dengan syariat Islam yang } \\
\text { baik dan sunat) dan rakyat (segala hasil } \\
\text { musyawarah atas kebulatan kehendak rakyat, } \\
\text { dari rakyat untuk rakyat). }\end{array}$ & $\begin{array}{l}\text { Nilai karakternyaadalah } \\
\text { tanggung jawab dan jujur. }\end{array}$ \\
\hline
\end{tabular}




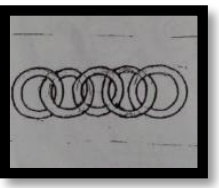

Motif Rante (rantai) melambangkan persatuan, Nilai karakternya adalah kesatuan dan kebersamaan masyarakat Gayo. Semangat Kebangsaan, Cinta Tanah Air, Bersahabat dan Tanggung Jawab.

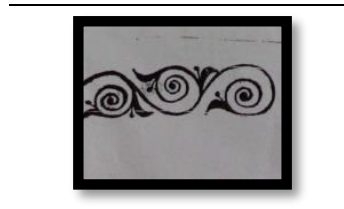
Motif Emun Beriring (awan beriringan) melambangkan satu kesatuan yang kokoh dalam kehidupan bermasyarakat dalam menetapkan diri dalam posisi kita berbeda.
Nilai karakter yang terkandung adalah demokratis, semangat kebangsaam dan bersahabat, peduli lingkungan dan cinta damai.

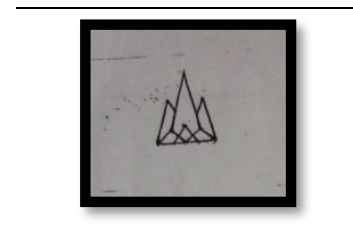
Motif Pucuk Rebung (tunas bambu) Motivasi memberikan pendidikan kepada generasi muda sebagai generasi penerus secara perlahan.
Motif tersebut syarat akan nilai disiplin, kerja keras, menghargai prestasi dan gemar membaca.

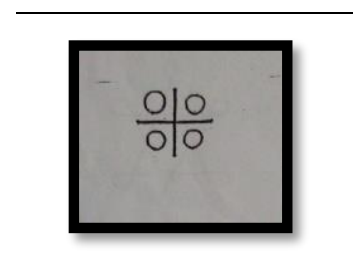 Motif Tekukur (terukur) melambangkan setiap mengambil keputusan harus dipertimbangkan dengan penuh arif dan bijaksana. Setiap Motif tersebut syarat akan nilai jujur dan tanggung jawab. perbuatan lebih dahulu berfikir untuk dipertimbangkan baik dan buruknya.

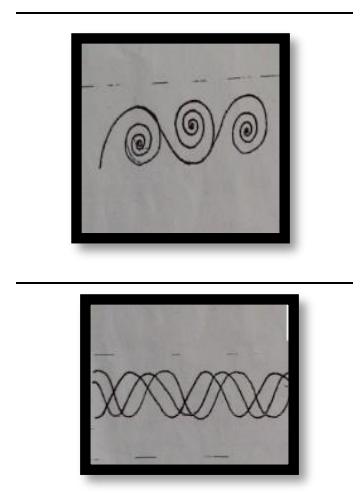
Motif Emun Berkune (awan bertanya)yang merupakan motif awan yang menekankan pada demokrasi dalam suatu mencari Motif tersebutsyaratakan nilaidemokrasi dan kebenaran, untuk mengambil keputusan dan tanggung jawab. dilaksanakan dengan tanggung jawab.
Motif Puter Tali melambangkan harus saling menyokong dan mendukung terhadap pekerjaan yang benar.

Motif tersebut memiliki maknanilaitoleransi, peduli lingkungan dan peduli sosial.

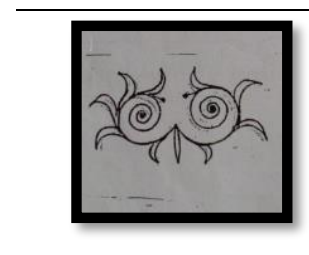

Motif Emun Berangkat merupakan lambang akan kesetiaan dalam masyarakat Gayo, kemanapun pergi tetap sejalan dan dimanapun berada tetap dalam satu kesatuan.
Nilai yang dapat dipetik adalah toleransi, semangat kebangsaan, dan bersahabat.

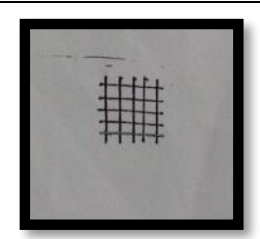

\footnotetext{
Motif Peger (pagar) merupakan lambang dari kehidupan masyarakat Gayo tetap berada dalam ketentuan Adat Gayo dan Syari'at Islam, diluar ketentuan tersebut tidak mendapat perlindungan.
} 
Sufandi Iswanto, Nurasiah, Hidayana Putri

Sulam Kerawang Gayo: Budaya Lokal, Bernilai Karakter dan Sebagai Identitas Bangsa

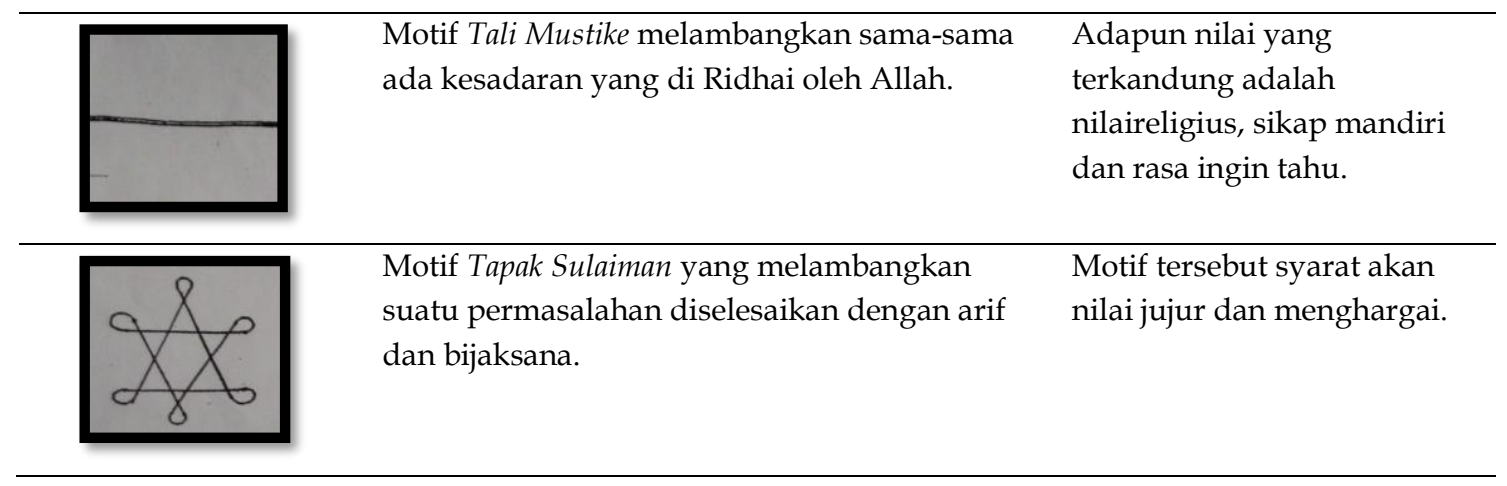

Motif-motif tersebut merupakan motif-motif yang diambil dari alam sekitar masyarakat Gayo tinggal. Setiap motif mencerminkan akan kearifan lokal masyarakat Gayo yang penuh dengan makna falsafah hidup secara tersirat mengrepresentasikan bagaimana manusia menjaga dirinya sendiri, hubungan dengan Allah, manusia dengan manusia, dan manusia dengan alam. Semua itu tidak terlepas dari kemahiran nenek moyang bangsa Gayo dalam menerawang dimasa depan dengan segala persoalan, pada akhirnya menyusun mozaik-mozaik nilai yang dilambangkan pada sebuah motif benda yang disebut kerawang Gayo.

Secara analisis, kebudayaan masyarakat Indonesia merupakan suatu sistem yang terbentuk dari kebudayaan nasional (national culture) dan kebudayaan lokal (local culture) (H. Geertz, 1981: Rina Devianty, 2017). Kebudayaan nasional adalah kebudayaan Timur yang mementingkan unsur-unsur seperti kerohanian, perasaan, dan saling membantu atau gotong royong (Mutakin, 1998). Lebih lanjut budaya atau kebudayaan nasional bisa juga dipahami sebagai integrasi budaya-budaya dari berbagai daerah yang ada di Indonesia yang dilakukan melalui dialetika kebudayaan yang akan menghasilkan sebuah kebudayaan baru (Budiman, 2002: Erond Litno Danimik, 2018). Semua hasil kebudayaan tersebut bisa dikatakan sebagai kebudayaan nasional. Jika merujuk pada status Indonesia sebagai negara multikultural maka selayaknya bahwa secara keseluruhan budaya lokal dari setiap daerah dan suku bangsa menjadi satu kesatuan dalam bingkai kebudayaan Indonesia.

Semua budaya yang lahir dan tumbuh berkembang di Indonesia dapat ditafsirkan sebagai identitas bangsa. Mengingat bahwa dalam setiap hasil budaya tersebut terdapat nilai-nilai dari kearifan lokal masyarakat Indonesia. Oleh karena itu, semua warisan budaya tersebut seyogyanya dapat ditafsirkan sebagai salah satu bentuk identitas bangsa Indonesia. Begitu juga dengan kerawang Gayo yang merupakan bagian dari identitas bangsa kita yaitu bangsa Indonesia. Nilai-nilai yang terkandung pada motif kerawang Gayo merupakan bentuk dari kearifan lokal masyarakat Gayo yang juga bagian dari Indonesia. Pada setiap motifnya mencerminkan akan adanya identitas bangsa Indonesia yang berakal, berbudi pekerti, arif dan bijaksana. Kerawang Gayo juga masuk kedalam bagian budaya intangible cultural heritage. Beberapa aspek sebuah budaya itu dikatakan intangible atau takbenda antara lain: (1) konsep mengenai benda itu, (2) pelambangan yang diwujudkan melalui benda yang dimaksud, (3) kebermaknaan yang berkaitan dengan fungsi atau kegunaannya, (4) isi pesan yang terkandung didalamnya, (5) teknologi dalam pembuatannya, dan (6) pola tingkah laku terkait dengan pemanfaatan benda tersebut (Sedyawati, 2007; Sujoko Efferin, 2014). 
Dilihat dari konsepnya, kerawang Gayo merupakan motif yang terdapat benda-benda kebudayaan masyarakat Gayo seperti pada motif ukir pada gerabah, motif ukir pada kayu rumah adat, motif pada anyaman, dan motif pada sulaman kain khas tradisional masyarakat setempat. Sedangkan dari pelambangan, kerawang Gayo sendiri disebut sebagai kain kebesaran masyarakat Gayo, pada masing-masing motifnya memiliki arti (makna tertentu) yang dijadikan sebagai falsafah hidup masyarakat setempat, hal itu juga yang menjadikan kerawang Gayo dianggap sakral. Dianggap bermakna sakral, maka kerawang Gayo jika mengikuti aturan dahulu hanya boleh digunakan pada acara-acara tertentu. Pesan yang terkandung didalamnya merupakan pesan yang berhubungan dengan hablum Minallah (hubungan manusia dengan Allah), hablum Minannas (hubungan manusia denga manusia), dan hubungan manusia dengan alam beserta mahluk hidupnya demi keselamatan dunia akhirat. Teknologi pembuatannya juga terbilang rumit, karena untuk membuat motifnya yang indah, dahulu teknik yang digunakan ialah dengan cara tradisional yaitu menyulam. Sebagaimana telah disampaikan sebelumnya akan nilai-nilainya maka tidak heran jika kerawang Gayo bisa dikatakan sebagai media yang menyampaikan aturan melalui simbol atau lambang yang mampu mengatur masyarakat Gayo dimanapun berada untuk tetap mengatur pola tingkah lakunya sesuai nilai-nilai kerawang Gayo baik dari motif maupun fungsinya (pemakaiannya).

Aspek-aspek yang terdapat pada kerawang Gayo sejalan dengan identitas dan jati diri bangsa Indonesia. Sebagai intangible yang memiliki arti penting dalam kehidupan masyarakat Gayo, atas peran masyarakat setempat maka kerawang Gayo tetap tumbuh dan berkembang sampai sekarang. Aspek historis, pengetahuan, kemahiran dan keterampilan tradisional dalam pembuatan kerawang Gayo juga telah menjadikan kerawang Gayo layak dikatakan sebagai identitas bangsa. Maka oleh karena itu pada tahun 2014, kerawang Gayo telah ditetapkan sebagai Warisan Budaya Tak Benda Indonesia oleh Kementerian Pendidikan dan Kebudayaan Republik Indonesia. Penetapan kerawang Gayo sebagai intangible cultural/heritage tidak terlepas dari peran masyarakat, komunitas budaya/adat, pemerintah daerah, dan Balai Pelestarian Nilai Budaya (BPNB) Aceh.

Memiliki ciri khas dan keunikan sendiri dan lahir dari suatu suku bangsa, kriteria tersebut sesuai juga dengan kriteria Intangible Culture Heritage (ICH) UNESCO yang berarti kerawang Gayo memiliki nilai-nilai budaya yang dapat meningkatkan kesadaran bangsa akan jati dirinya yang mampu mengampu persatuan bangsa. Dengan demikian posisi kerawang Gayo pada saat ini semakin kuat dan telah diakui secara nasional menjadi budaya takbenda dan sebagai identitas bangsa. Hal tersebut diperkuat dengan dikeluarkannya Keputusan Menteri Pendidikan dan Kebudayaan Republik Indonesia Nomor 270/P/2014 tentang Penetapan Warisan Budaya Takbenda Indonesia Tahun 2014 pada tanggal 8 Oktober 2014, Kerawang Gayo sebagai kerajinan tradisional dari masyarakat Gayo. Dengan demikian patut kiranya kerawang tetap kita jaga secara bersama karena kerawang sebagai identitas bangsa. 
Sufandi Iswanto, Nurasiah, Hidayana Putri

Sulam Kerawang Gayo: Budaya Lokal, Bernilai Karakter dan Sebagai Identitas Bangsa

\section{Simpulan}

Sulam kerawang Gayo merupakan salah satu hasil kebudayaan dari sekian banyak hasil kebudayaan masyarakat Gayo. Motif kerawang Gayo sendiri diadopsi dari alam sekitar masyarakat Gayo tinggal. Semua bentuk motif tersebut merefresentasikan keadaan alam Dataran Tinggi Gayo yang subur, sejuk karena diapit oleh bukit-bukit barisan. Setiap motif kerrawang Gayo juga merefresentasikan akan nilai-nilai budaya dan karaktermasyarakat lokal. Masyarakat Gayo menjadikan kerrawang Gayo sebagai atribut dan falsafah hidup. Dilihat dari maknanya, motif-motif kerrawang Gayo seperti motif mata lo, sarakopat, rante, eumunberkune, putertali, peger, dan lain-lainnya sejalan dengan perumusan 18 nilai-nilai karakter dan pendidikan bangsa di sekolah (Kurikulum 2013). Sebagai negara yang memiliki banyak ragam budaya daerah, kita harus saling menghargai dan mengambil sisi baik dari masing-masing budaya tersebut.

\section{Daftar Rujukan}

Asnah, H. H. A. (1996). C. Snouck Hugronje: Gayo Masyarakat dan Kebudayaan Awal abad ke-20. Jakarta: Balai Pustaka.

Bailey, K. D. (1982). Methods of Social Research (2nd ed.). Minnesota: University of Minnesota Free Press.

Budiman, H. (2002). Lubang Hitam Kebudayaan. Yogyakarta: Penerbit Kanisius.

Bungin, B. (2003). Analisis Data Penelitian Kualitatif. Jakarta: PT RajaGrafindo Persada.

Erlinda. (2016). Menapak Indang Sebagai Budaya Surau (I; A. Gunawan, Ed.). Kota Pandang Panjang: LPPMPP Isi Padang Panjang.

Erond Litno Danamik. 2018. Rekayasa Budaya dan Dinamika Sosial. Jurnal of Education, Humaniora and Social (JEHSS), 1(2).

Fadhillah. (1991). Perkembangan Kerawang Gayo dalam Menumbuhkan Wiraswasta. Banda Aceh.

Ferawati. 2013. Motif Karawang Gayo pada Busana Adat Pengantin di Aceh Tengah. Jurnal Ekspresi Seni, 15(1).

Geertz, C. (1992). Tafsir Kebudayaan. Jakarta: Penerbit Kanisius.

Geertz, H. (1981). Aneka Budaya dan Komunitas di Indonesia. Jakarta: Yayasan Ilmu-Ilmu Sosial dan FIS UI.

Handoyo, E. (2015). Studi Masyarakat Indonesia. Yogyakarta: Ombak.

I Ketut Sudarsana. 2017. Relevansi Nilai Pendidikan Karakter dalam Geguritan Suddhamala 
DIAKRONIKA 20 (2) 2020

ISSN: 1411-1764 (Print) | 2620-9446 (Online)

untuk Meningkatkan Mutu Pendidikan. Jurnal Penjamin Mutu, 3(2).

Imam Baehaqie. 2014. Jenang Manca Warna Sebagai Simbol Multikulturalisme Masyarakat Jawa. Jurnal Komunitas, 6(1).

Iswanto, S., Sufi, R., \& Abdullah, T. (2012). Perkembangan Kerawang Gayo di Aceh Tengah (19042012). Universitas Syiah Kuala.

Iswanto, S., Warto, \& Djono. (2015). Pengembangan Bahan Ajar Sejarah Lokal Berbasis Nilai-Nilai Sulam Kerawang Gayo untuk Meningkatkan Karakter Bangsa Siswa Kelas XI SMA Negeri Kabupaten Bener Meriah. Universitas Sebelas Maret.

J. R. Raco. 2010. Metode Penelitian Kualitatif. Jakarta: PT. Gramedia Widiasarana.

Juliawati Ningsih. 2018. Perbedaan Motif Kerawang Gayo Lues dan Aceh Tengah. Jurnal Ilmiah Mahasiswa Prodi Seni Drama, 3(4) 356-367.

Khalisuddin, Setyantoro, A. S., Gayosia, A. P., Bathin, W. R., \& As, N. B. (2012). Kopi dan Kehidupan Sosial Budaya Masyarakat Gayo (Jamhuri, Ed.). Banda Aceh: BPNB Aceh.

Koentjaraningrat. (1990). Pengantar Ilmu Antropologi (8th ed.). Jakarta: PT Rineka Cipta.

Leigh, B. (1989). Tangan-Tangan Terampil: Seni Kerajinan Aceh/Hands of Time: The Crafts of Aceh. Jakarta: Penerbit Djambatan.

M. Bahar Akkase Teng. 2017. Filsafat Kebudayaan dan Sastra (Dalam Perspektif Sejarah). Jurnal Ilmu Budaya, 5(1).

M. Muslich. 2004. Pandangan Hidup dan Simbol-simbol dalam Budaya Jawa. Jurnal Millah, 3(2).

Maran, R. R. (2010). Manusia E Kebudayaan dalam Pespektif Ilmu Budaya Dasar (Ed.3 ed.). Jakarta: PT Rineka Cipta.

Mustari, M. (2014). Nilai Karakter Refleksi untuk Pendidikan. Jakarta: PT RajaGrafindo Persada.

Mutakin, A. (1998). Studi Masyarakat Indonesia. Jakarta: Departemen Pendidikan dan Kebudayaan.

Nurdien Harry Kistanto. 2015. Tentang Konsep Budaya. Jurnal Kajian Kebudayaan, 10(2).

Panjaitan, A. P., Darmawan, A., Maharani, Purba, I. R., Rachmad, Y., \& Simajuntak, R. (2014). Korelasi Kebudayaan \& Pendidikan: Membangun Pendidikan Berbasis Budaya Lokal (I). Jakarta: Yayasan Pustaka Obor Indonesia.

Prayitno, \& Trubus. (2004). Etika Kemajemukan: Solusi Strategis Merenda Kebersamaan dalam Bingkai Masyarakat Majemuk (Ed. 2). Jakarta: Penerbit Universitas Trisakti. 
Sufandi Iswanto, Nurasiah, Hidayana Putri

Sulam Kerawang Gayo: Budaya Lokal, Bernilai Karakter dan Sebagai Identitas Bangsa

Rida Safuan Selian. 2007. Upacara Perkawinan "Ngerje" Kajian Estetika Tradisional Suku Gayo di Dataran Tinggi Gayo Kabupaten Aceh Tengah. Tesis UNNES.

Rina Devianty. 2017. Bahasa Sebagain Cerminan Kebudayaan. Jurnal Tarbiyah, 24(2).

Rita Fitri. 2020. Makna dan Funsi Motif Kerawang Gayo Pada Upuh Uleh-uleh di Kecamatan Kebanyakan Kabupaten Aceh Tengah. Prosiding Seminar Nasional Pendidikan Antropologi (SEMNASPA), Vol 1.

Samani, M., \& Hariyanto. (2012). Konsep dan Model Pendidikan Karakter. Bandung: Remaja Rosdakarya.

Sedyawati, E. (2007). Budaya Indonesia: Kajian Arkeologi, Seni, dan Sejarah (Ed.1 ed.). Jakarta: PT RajaGrafindo Persada.

Shabri. (2000). Budaya Masyarakat Suku Bangsa Gayo di Kabupaten Aceh Tengah. Banda Aceh: Proyek Pengkajian dan Pembinaan Nilai-Nilai Budaya.

Sufi, R., \& Wibowo, A. B. (2013). Gayo: Sejarah dan Legenda. Banda Aceh: Badan Arsip dan Perpustakaan Aceh.

Sugiyono. (2010). Metode Penelitian Kuantitatif, Kuantitatif, dan RED. Bandung: Alfabeta.

Sujoko Efferin. 2014. Memahami Perilaku Stake Holders Indonesia dalam Adopsi IFRS Tinjauan Aspek Kepentingan, Bahasa, dan Budaya. Jurnal Akuntansi dan Keuangan Indonesia, 11(2).

Teuku Muda Aryadi. 2003. Pendidikan Ilmu Kebudayaan. Jurnal Wacana Senirupa 3(6).

Wiradnyana, K., \& Setiawan, T. (2011). Gayo Merangkai Identitas (Ed. 1). Jakarta: Yayasan Pustaka Obor Indonesia.

Yaumi, M. (2014). Pendidikan Karakter Landasan Pilar dan Implementasi. Jakarta: Prenada Media Group. 